\title{
Tunable construction of transition metal-coordinated helicene cages
}

\author{
Yongle Ding ${ }^{\mathrm{a}, \mathrm{b}}$, Chengshuo Shen ${ }^{\mathrm{a}, \text { * }}$, Fuwei Gan ${ }^{\mathrm{a}}$, Jinghao Wang ${ }^{\mathrm{a}}$, Guoli Zhang ${ }^{\mathrm{a}}$, Lingling Li ${ }^{\mathrm{b}}$, Mouhai \\ Shu ${ }^{\mathrm{a}}$, Bangshang Zhu ${ }^{\mathrm{b}, *}$, Jeanne Crassous ${ }^{\mathrm{c}}$, Huibin Qiu ${ }^{\mathrm{a}, *}$ \\ ${ }^{a}$ School of Chemistry and Chemical Engineering, Frontiers Science Center for Transformative Molecules, State Key Laboratory of Metal Matrix Composites, \\ Shanghai Jiao Tong University, Shanghai 200240, China \\ ${ }^{b}$ Instrumental Analysis Center, Shanghai Jiao Tong University, Shanghai 200240, China \\ ${ }^{c}$ Univ Rennes, Institut des Sciences Chimiques de Rennes, UMR CNRS 6226, Campus de Beaulieu, Rennes 35042, France
}

\section{ABSTRACT}

\begin{abstract}
We report a facile and tailored method to prepare globally twisted chiral molecular cages through tunable coordination of bis-bipyridine-terminated helicene ligands to a series of transition metals including $\mathrm{Fe}(\mathrm{II}), \mathrm{Co}(\mathrm{II}), \mathrm{Ni}(\mathrm{II})$ and $\mathrm{Zn}$ (II). This system shows an efficient remote transfer of stereogenecity from the helicene core to the bipyridine-metal coordination sites and subsequently the entire cages. While the Fe(II), $\mathrm{Co}$ (II) and $\mathrm{Ni}$ (II)-derived $\mathrm{M}_{2} \mathrm{~L}_{3}$ (M for metal and $\mathrm{L}$ for ligand) cages exhibit quasi-reversible redox features, the $\mathrm{Zn}$ (II) analogues reveal prominent yellow circularly polarized luminescence. Interestingly, with the addition of $\mathrm{Na}_{2} \mathrm{SO}_{4}$, the $\mathrm{Zn}_{2} \mathrm{~L}_{3}$ cages reassemble into sextuple-stranded $\mathrm{Zn}_{6} \mathrm{~L}_{6}\left(\mathrm{SO}_{4}\right)_{4}$ cages in which three $\mathrm{Zn}_{2} \mathrm{~L}_{2}$ units
\end{abstract}

Keywords:

Helicene

Coordination cage

Chiral

Global helicity

Circularly polarized luminescence
Molecular cages with well-defined structures and internal cavities have raised abundant interest in recent years $[1,2]$. The synthesis of these intrinsic hollow species normally involved tailored connections of molecular building blocks either through covalent bonding or coordination to metals [3-9]. The flexible linkage chemistry along with the diversity in building blocks has favored an unprecedentedly wide access to cages with tunable geometries and functions [10-12]. Amongst, chiral molecular cages have drawn significant attentions due to their potential applications in chiral sensing, chiral separation and asymmetric catalysis [13-17]. So far, a series of chiral molecular building blocks have been adopted to enantioselectively create these chiral entities [18,19]. However, the facile construction of chiral cages with highly extended, globally distorted unsymmetrical structures remains a great challenge, majorly as a consequence that the conventional chiral molecular building blocks normally fail to efficiently transfer the local chirality to the whole cage skeletons in spite of a few advances (mainly in helicates) achieved by axially chiral building blocks [20-22].

Helicenes are a type of chiral molecules constituted by orthofused aromatic rings with unique helical shapes [23-25]. Helicene-cored molecule generally exhibits an apparent threedimensionally twisted structure with chirality effectively expressed across the whole molecule along with the remote substituents $[26,27]$. Normally, carbo[n]helicenes with the number of rings $(n)$ larger than 5 possess stable configuration against racemization [28]. We have previously demonstrated that helicene derivatives can serve as building blocks to construct covalent organic cages, which presented a globally distorted, triple-stranded helical structure with high recognition ability towards chiral guest molecules [29]. Clever et al. further synthesized bis-pyridine-terminated helicenes and used them as * Corresponding authors.

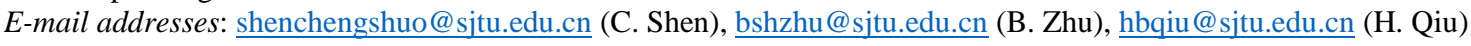

ligands to prepare a series of Pd-coordinated chiral cages, which also showed promising guest recognition features [30]. However, the structure and function of these helicene cages is so far limited by the diversity of helicene precursor and linkage chemistry. Herein, we introduce two 2,2'-bipyridine moieties onto the 4,13positions of [6]helicene through two alkyl bridges and develop a globally bent ligand, which favors a tunable coordination to a variety of transition metals with efficient transfer of stereogenecity to the coordination sites, and hence allow the formation of coordination cages with unique triple-stranded binuclear or sextuple-stranded hexanuclear structures and distinctive properties (Scheme 1).

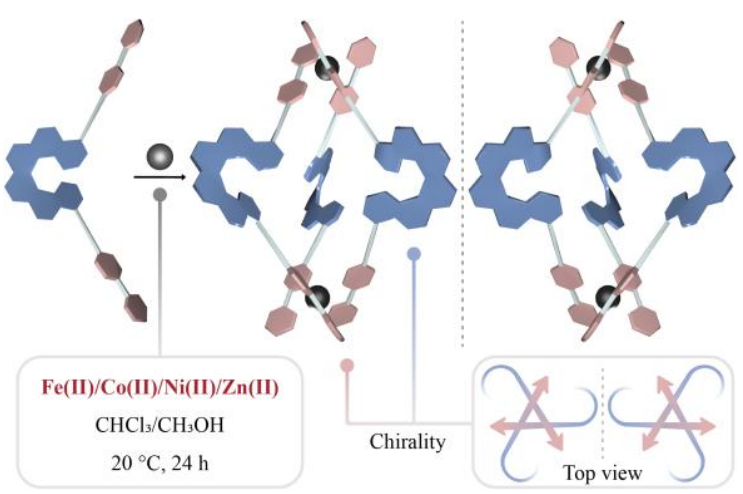

Scheme 1. Schematic representation for the synthesis of helicene-derived chiral coordination cages.

We first synthesized the helicene ligand through a Sonogashira coupling reaction between 5-bromo-2,2'-bipyridine and 4,13-diethynyl[6]helicene in both racemic and enantiopure forms (Scheme S1 in Supporting information). The resulting ligand showed a bent, non-planar structure with two extended 
bipyridine arms organized in a $\vec{\Delta}$ (for bis-bipyridine-terminated $(P)$-helicene, i.e., $(P)$-ligand) or $\vec{\Lambda}$ (for bis-bipyridine-terminated $(M)$-helicene, i.e., $(M)$-ligand) chiral fashion (the dihedral angle between two arms was $c a .165^{\circ}$, Figs. S4-1 and S4-15 in Supporting information) [31]. We then mixed the ligand with $\mathrm{Fe}\left(\mathrm{CF}_{3} \mathrm{SO}_{3}\right)_{2}$ in a ratio of $3: 2$, and subsequently observed an immediate change of color from paled-yellow to deep-red, corresponding to a fast chelating process between the bipyridine groups and $\mathrm{Fe}(\mathrm{II})$ [32]. The collected product showed a clean and simple ${ }^{1} \mathrm{H}$ NMR pattern with the same number of proton environments as the ligand (Fig. 1a, Figs. S2-1, S3-1 and S3-2 in
Supporting information). Notably, protons $H-22$ and $H-28$ adjacent to the nitrogen atoms drastically shifted upfield from 8.98 and $8.73 \mathrm{ppm}$ to 7.92 and $7.30 \mathrm{ppm}$, respectively, demonstrating the complexation between the bipyridine modules and $\mathrm{Fe}(\mathrm{II})$ [33]. Electrospray ionization high resolution mass spectrometry (ESI-HRMS) revealed three main peaks at $\mathrm{m} / \mathrm{z}=$ $541.3949(z=4), 771.5036(z=3)$ and $1231.7511(z=2)$, which can be indexed as $\left[\mathrm{Fe}_{2} \mathrm{~L}_{3}\right]^{4+}, \quad\left[\mathrm{Fe}_{2} \mathrm{~L}_{3}\left(\mathrm{CF}_{3} \mathrm{SO}_{3}\right)\right]^{3+}$ and $\left[\mathrm{Fe}_{2} \mathrm{~L}_{3}\left(\mathrm{CF}_{3} \mathrm{SO}_{3}\right)_{2}\right]^{2+}$, respectively ( $\mathrm{L}$ for the helicene ligand, Fig. $1 b)$. $\mathbf{a}$

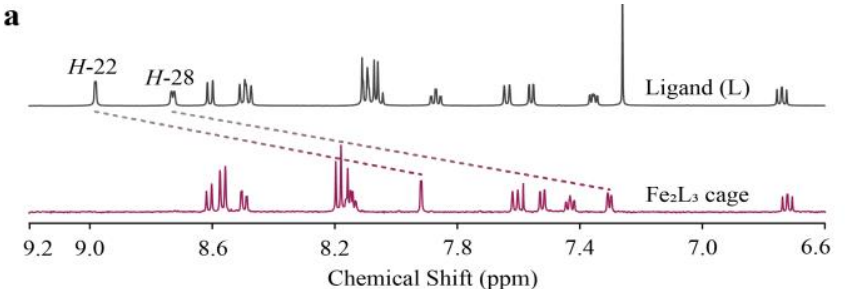

b

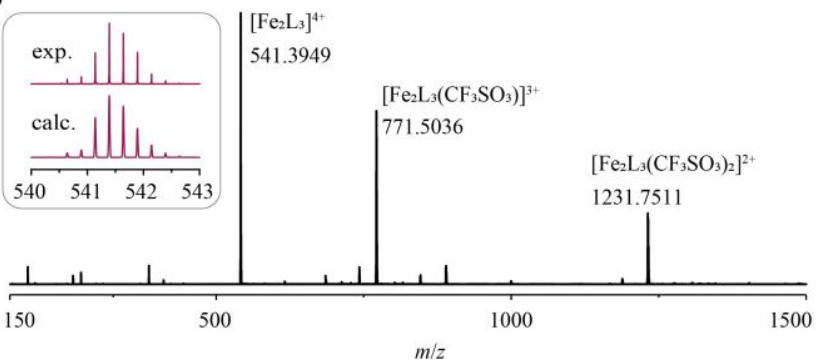

c

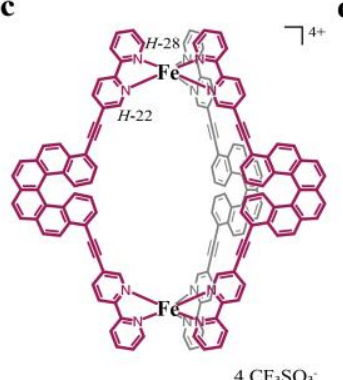

d

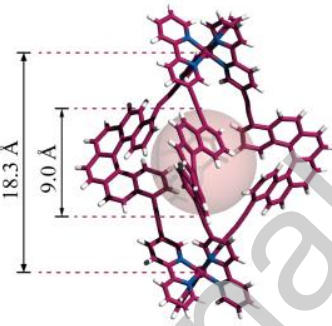

(M) $-\mathrm{Fe}_{2} \mathrm{~L}$ cage e
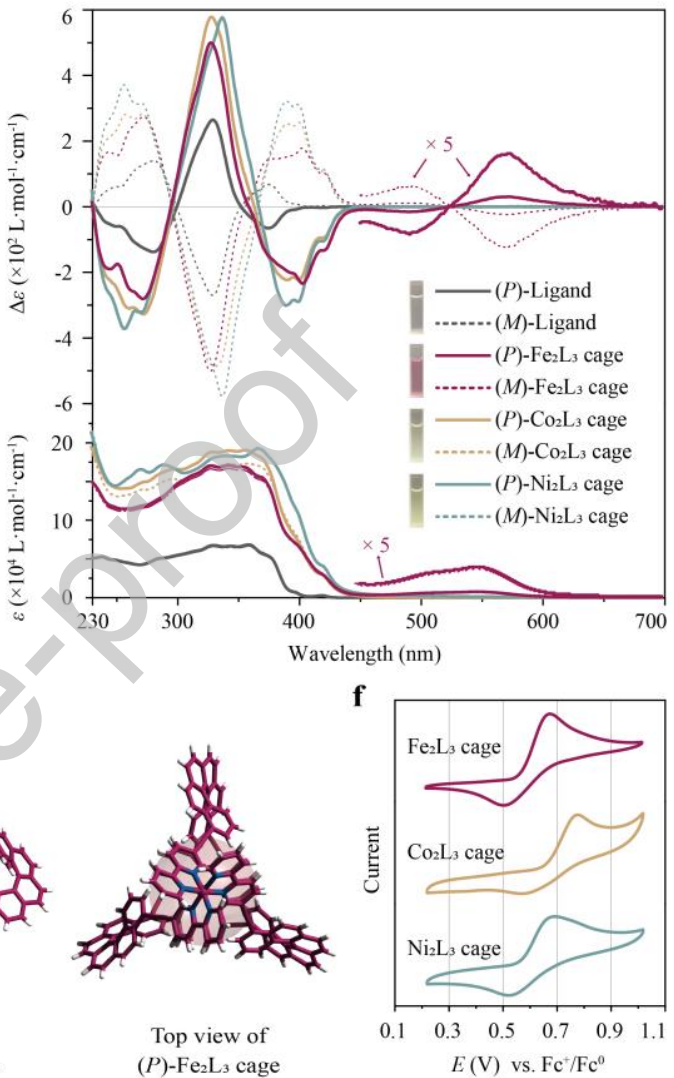

f

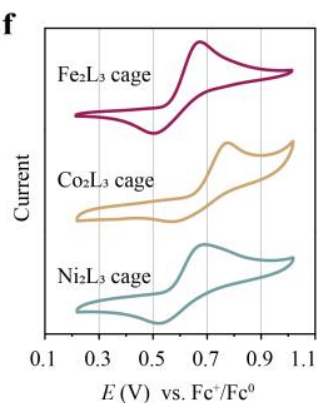

Fig. 1. $\mathrm{Fe}(\mathrm{II})-\mathrm{Co}(\mathrm{II})$ - and $\mathrm{Ni}(\mathrm{II})$-based $\mathrm{M}_{2} \mathrm{~L}_{3}$ cages. (a) ${ }^{1} \mathrm{H} \mathrm{NMR}$ spectrum of (rac)-Fe $\mathrm{L}_{3}$ cage $\left(500 \mathrm{MHz}\right.$, $\left.\mathrm{CD}{ }_{3} \mathrm{CN}, 298 \mathrm{~K}\right)$ with comparison to ( rac)-bis-bipyridine-terminated helicene ligand (L) (500 MHz, $\mathrm{CDCl}_{3}, 298 \mathrm{~K}$ ). (b) ESI-HRMS spectrum of (rac)-Fe $\mathrm{L}_{3}$ cage. (c) $\mathrm{Chemical}$ structure of $\mathrm{Fe}_{2} \mathrm{~L}_{3}$ cage. (d) Crystal structures of $(M)$ - and $(P)-\mathrm{Fe}_{2} \mathrm{~L}_{3}$ cages with the largest possible spheres inside the cavity. (e) UV-vis (bottom) and ECD (top) spectra of enantiopure helicene ligands (in $\mathrm{CH}_{2} \mathrm{Cl}_{2}, c=2 \times 10^{-5} \mathrm{~mol}_{/} \mathrm{L}$ ) and $\mathrm{Fe}_{2} \mathrm{~L}_{3}, \mathrm{Co}_{2} \mathrm{~L}_{3}$ and $\mathrm{Ni}_{2} \mathrm{~L}_{3}$ cages (in $\mathrm{CH}_{3} \mathrm{CN}_{\text {, }}$ $\left.c=1 \times 10^{-5} \mathrm{~mol} / \mathrm{L}\right)$. (f) Cyclic voltammograms of racemic $\mathrm{Fe}_{2} \mathrm{~L}_{3}, \mathrm{Co}_{2} \mathrm{~L}_{3}$ and $\mathrm{Ni}_{2} \mathrm{~L}_{3}$ cages $\left(1 \times 10^{-3} \mathrm{~mol} / \mathrm{L}\right.$ in $\mathrm{CH}{ }_{3} \mathrm{CN}$, with $1 \times 10^{-1} \mathrm{~mol} / \mathrm{L}$ of $n-$ $\mathrm{Bu}_{4} \mathrm{NPF}_{6}$ as the electrolyte, scan rate $\left.=50 \mathrm{mV} / \mathrm{s}\right)$.

Single-crystal X-ray diffraction further confirmed the yield of $\mathrm{Fe}_{2} \mathrm{~L}_{3}$ coordination cages (Fig. 1c), in which three helicene ligands were bridged by two Fe atoms (distance of $c a$. $18.3 \AA$ ) and formed a triple-stranded helical structure (Fig. 1d). The three surrounding helicene ligands created a sizeable internal cavity, which could accommodate a sphere with a diameter of $c a .9 \AA$ (with its surface just attaching the van der Waals surface of the cage framework). For the cage derived from the $(P)$-ligand (i.e., $(P)-\mathrm{Fe}_{2} \mathrm{~L}_{3}$ ), both two Fe-bipyridine coordination sites were in $\Delta$ stereogenecity, and the whole cage framework adopted a $P$ helical conformation [34]. Similarly, in the enantiomeric mirror series, the cage formed by the $(M)$-ligand (i.e., $(M)-\mathrm{Fe}_{2} \mathrm{~L}_{3}$ ) displayed an $M$ helical shape with two Fe-bipyridine sites solely in $\Lambda$ stereogenecity. It seemed that the helicene core substantially dominates the stereogenecity of the coordination domains as well as the helicity of the entire cage, which renders the cage formation reaction highly diastereoselective and prevents the formation of other diastereomers. This was actually also demonstrated by the simple ${ }^{1} \mathrm{H}$ NMR spectrum, which was indicative of the absence of other isomers. Such efficient remote transfer of stereogenic information probably can be interpreted by the minimal-energy stacking of the relatively rigid, globally bent helicene ligands.

The $\mathrm{Fe}_{2} \mathrm{~L}_{3}$ cage showed a group of intensive UV-vis absorption bands from 230 to $450 \mathrm{~nm}$ (Fig. 1e), roughly reprinting the nature of the helicene ligand. The ECD signals in the region of $360 \sim 450 \mathrm{~nm}$ were dramatically enhanced compared to that of the helicene ligands, which was probably due to the coordination to $\mathrm{Fe}(\mathrm{II})$. The $\mathrm{Fe}_{2} \mathrm{~L}_{3}$ cage also revealed a distinctive absorption band with moderate intensity in the region of $450 \sim 650 \mathrm{~nm}$, which could be attributed to the metal to ligand charge transfer (MLCT) from the Fe(II) centers to the bipyridine 
modules [35,36]. The corresponding ECD curves were resolved in a bisignate fashion. The $(P)-\mathrm{Fe}_{2} \mathrm{~L}_{3}$ cage displayed a positive Cotton effect at $570 \mathrm{~nm}$ and a negative one at $490 \mathrm{~nm}$, which is in accordance with the $\Delta$ configuration of the Fe-bipyridine coordination sites [35]. Meanwhile, the $(M)-\mathrm{Fe}_{2} \mathrm{~L}_{3}$ cage presented a mirror-imaged ECD curve, indicating a $\Lambda$ configuration.

We further switched the transition metals to $\mathrm{Co}(\mathrm{II})$ and $\mathrm{Ni}(\mathrm{II})$ and obtained yellow-colored products. ESI-HRMS analysis (Figs. S3-4 and S3-5) and/or single-crystal X-ray diffraction (Fig. S4-4) confirmed the formation of $\mathrm{Co}_{2} \mathrm{~L}_{3}$ and $\mathrm{Ni}_{2} \mathrm{~L}_{3}$ cages in a triplestranded helical shape with the selective formation of stereogenic coordination sites analogous to the $\mathrm{Fe}_{2} \mathrm{~L}_{3}$ cage. The $\mathrm{Co}_{2} \mathrm{~L}_{3}$ and $\mathrm{Ni}_{2} \mathrm{~L}_{3}$ cages revealed similar UV-vis and ECD spectra to the $\mathrm{Fe}_{2} \mathrm{~L}_{3}$ cage in the shorter wavelength region $(<450 \mathrm{~nm})$, but in the longer wavelength region (> $450 \mathrm{~nm}$ ) no obvious absorption band was detected (Fig. 1e), indicating a distinct metal to ligand electron transition mechanism [35]. Besides, due to the introduction of electrochemically active metal coordination sites [37,38], all these three helicene cages exhibited a single redox event at $+0.68\left(\mathrm{Fe}_{2} \mathrm{~L}_{3}\right.$ cage $),+0.78\left(\mathrm{Co}_{2} \mathrm{~L}_{3}\right.$ cage $)$ and $+0.69 \mathrm{~V}$ $\left(\mathrm{Ni}_{2} \mathrm{~L}_{3}\right.$ cage) vs. $\mathrm{Fc}^{+} / \mathrm{Fc}^{0}$, respectively, which appeared to be quasi-reversible (Fig. 1f).

Similarly, with the addition of $\mathrm{Zn}$ (II) salts into the solution of the bis-bipyridine-helicene ligand, we obtained a yellow-colored compound, which showed a simple ${ }^{1} \mathrm{H}$ NMR curve (Fig. S3-6) and well-resolved ESI-HRMS peaks at $m / z=546.1373(z=4$, Fig. 2a). Single-crystal X-ray diffraction again confirmed the formation of $\mathrm{Zn}_{2} \mathrm{~L}_{3}$ cages with homologous triple-stranded helical topology (Fig. 2b). ECD spectra further reflected the chiral fashion of the resulting $\mathrm{Zn}_{2} \mathrm{~L}_{3}$ cage in solution (Fig. 2c), which was similar to the $\mathrm{Co}_{2} \mathrm{~L}_{3}$ and $\mathrm{Ni}_{2} \mathrm{~L}_{3}$ cage. Like other $\mathrm{Zn}$ bipyridine coordination complexes [39], the $\mathrm{Zn}_{2} \mathrm{~L}_{3}$ cages showed yellow luminescence $\left(\lambda_{\max }=580 \mathrm{~nm}\right.$, Fig. 2d) under the irradiation of UV light, which was considerably bathochromically shifted compared with the blue luminescence of the helicene ligand $\left(\lambda_{\max }=430 \mathrm{~nm}\right)$. As a result of the global transfer of stereogenic information throughout the whole cage, these $\mathrm{Zn}_{2} \mathrm{~L}_{3}$ cages presented prominent circularly polarized luminescence (CPL) with dissymmetric factor $g_{\text {lum }}$ of \pm 0.002 at $580 \mathrm{~nm}$ (negative for $(P)-\mathrm{Zn}_{2} \mathrm{~L}_{3}$ cage and positive for $(M)-\mathrm{Zn}_{2} \mathrm{~L}_{3}$ cage, i.e., with the signs in agreement with the lowest ECDactive band).

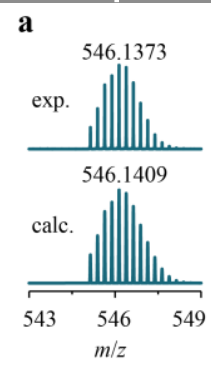

c

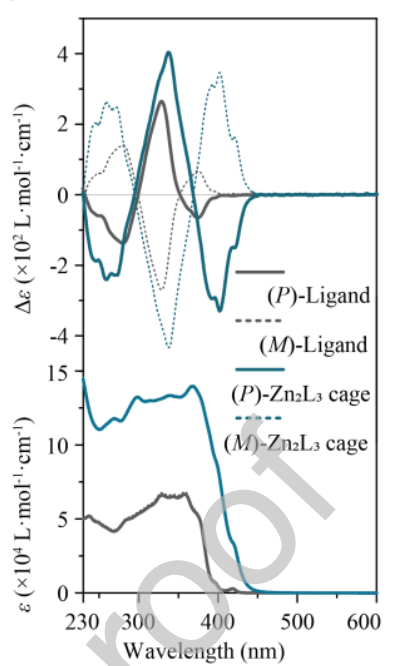

\section{b}

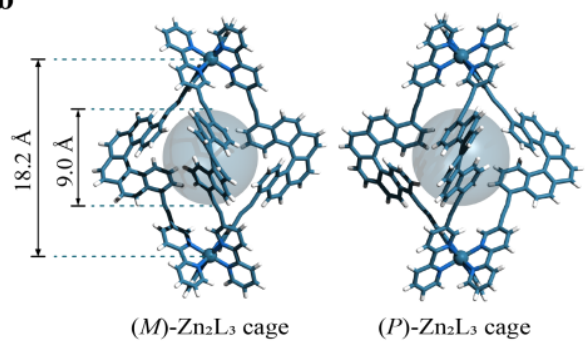

d
Fig, 2. $\mathrm{Zn}_{2} \mathrm{~L}_{3}$ cages. (a) ESI-HRMS and calculated mass spectra of (rac)- $\mathrm{Zn}_{2} \mathrm{~L}_{3}$ cages. (b) Crystal structures of $(M)$ - and $(P)-\mathrm{Zn}_{2} \mathrm{~L}_{3}$ cages with the largest possible spheres inside the cavity. (c) UV-vis (bottom) and ECD (top) spectra of enantiopure $\mathrm{Zn}_{2} \mathrm{~L}_{3}$ cages (in $\mathrm{CH}_{3} \mathrm{OH}, c=4 \times 10^{-5} \mathrm{~mol} / \mathrm{L}$, compared with the helicene ligands). (d) Fluorescence (bottom) and CPL (top) spectra of enantiopure helicene ligands and $\mathrm{Zn}_{2} \mathrm{~L}_{3}$ cages. The inset photographs show their luminescence under irradiation at $365 \mathrm{~nm}$.

Interestingly, when treating the $\mathrm{Zn}_{2} \mathrm{~L}_{3}$ cage solution with $\mathrm{Na}_{2} \mathrm{SO}_{4}$ powder, we obtained a green-luminescent compound with a splitting of all proton environments into two sets in the ${ }^{1} \mathrm{H}$ NMR spectrum (Fig. 3b). For example, the signals of protons $H$ 22 and $H-28$ at 8.56 and $8.01 \mathrm{ppm}$ were split, with one set drastically shifted upfield to 7.52 and $7.03 \mathrm{ppm}$ and the other set moved downfield to 9.98 and 9.39 ppm, respectively. ESI-HRMS showed that this new composite possesses a relatively large molecular weight ( $m=4884.7608$, Figs. S3-15 in Supporting information), which can be assigned as $\mathrm{Zn}_{6} \mathrm{~L}_{6}\left(\mathrm{SO}_{4}\right)_{4}$. Singlecrystal X-ray diffraction of the racemic product further illustrated a six-stranded helical structure with the integration of three tilted homochiral $\mathrm{Zn}_{2} \mathrm{~L}_{2}$ macrocyclic modules by two pairs of sulfates aligned on the vertical axis (Figs. $3 a$ and $c$ ). The intricate trigonal-bipyramid-like $\mathrm{Zn}_{3}\left(\mathrm{SO}_{4}\right)_{2}$ cluster also revealed a helical conformation with the two $\mathrm{SO}_{4}$ vertexes slightly twisted with each other. The neighboring helicene ligands belonging to two $\mathrm{Zn}_{2} \mathrm{~L}_{2}$ modules were closely packed in a short distance of $c a$. 3.6 $\AA$ and revealed unsymmetrical offset $\pi-\pi$ interactions (Figs. S416 in Supporting information), which rendered a more sophisticated environment and hence the split of the ${ }^{1} \mathrm{H}$ NMR signals. This giant cage showed an expanded cavity compared with the original $\mathrm{Zn}_{2} \mathrm{~L}_{3}$ cage and could host a sphere with a diameter of ca. $10.0 \AA$.

By gradual addition of $\mathrm{Na}_{2} \mathrm{SO}_{4}$ into the $\mathrm{Zn}_{2} \mathrm{~L}_{3}$ cage solution in a mixture of $\mathrm{CD}_{3} \mathrm{OD} / \mathrm{CDCl}_{3}$, the ${ }^{1} \mathrm{H} \mathrm{NMR}$ spectra revealed an apparent evolution with the rising of the $\mathrm{Zn}_{6} \mathrm{~L}_{6}\left(\mathrm{SO}_{4}\right)_{4}$ cage and the free ligand in a molar ratio of $1: 3$, and the simultaneous 
consumption of the $\mathrm{Zn}_{2} \mathrm{~L}_{3}$ cage precursor (Figs. S3-16 in Supporting information). This strongly indicated that each $\mathrm{Zn}_{6} \mathrm{~L}_{6}\left(\mathrm{SO}_{4}\right)_{4}$ cage was assembled from three $\mathrm{Zn}_{2} \mathrm{~L}_{3}$ cages via ligand exchange to sulfates, with the corresponding release of three free helicene ligands. Notably, no obvious peaks for other intermediates were observed, demonstrating that this assembly process might undergo in a cooperative pathway [40].

The $\mathrm{Zn}_{6} \mathrm{~L}_{6}\left(\mathrm{SO}_{4}\right)_{4}$ cages showed similar absorption bands as the $\mathrm{Zn}_{2} \mathrm{~L}_{3}$ cages, suggesting that the major electron transition modes were generally preserved in this new coordination complex. However, the $\mathrm{Zn}_{6} \mathrm{~L}_{6}\left(\mathrm{SO}_{4}\right)_{4}$ cages presented intense ECD bands in the region of $370 \sim 450 \mathrm{~nm}$ with $\Delta \varepsilon_{\max }= \pm 1040$ $\mathrm{L} \cdot \mathrm{mol}^{-1} \cdot \mathrm{cm}^{-1}$, which was $c a$. 1.6 folders of the $\mathrm{Zn}_{2} \mathrm{~L}_{3}$ cages (with consideration of the number of helicene ligands, Fig. 3d). Such drastic enhancement might be resulted from the unique chiral packing of the helicene ligands as well as the twisted structure of the whole $\mathrm{Zn}_{6} \mathrm{~L}_{6}\left(\mathrm{SO}_{4}\right)_{4}$ cage. On the other hand, the changes on the coordination sites apparently affected the luminescence property and hence the maximum emission hypsochromically shifted to $520 \mathrm{~nm}$. Notably, the $\mathrm{Zn}_{6} \mathrm{~L}_{6}\left(\mathrm{SO}_{4}\right)_{4}$ cages revealed remarkable CPL with $g_{\text {lum }}$ of \pm 0.004 (doubled compare to the $\mathrm{Zn}_{2} \mathrm{~L}_{3}$ cages, Fig. 3e vs. Fig. 2d).

In conclusion, we have prepared a series of chiral coordination cages via facile coordination of bis-dipyridine-terminated helicene ligands with a variety of transition metals. The flexible selection of metal centers substantially enriches the chemistry and functions (potentially for electrochemical or luminescencesensitive recognition and separation of chiral guest molecules) of the resultant cages. Besides, the relatively dynamic association between the bipyridine modules and $\mathrm{Zn}$ (II) may also favor the fabrication of more complex chiral coordination cages via ligand exchanges using other suitable inorganic and organic species. We are currently exploring the construction of other distinctive chiral molecular cages utilizing the diverse helicene coordination chemistry [41], aiming at innovative structures and functions.
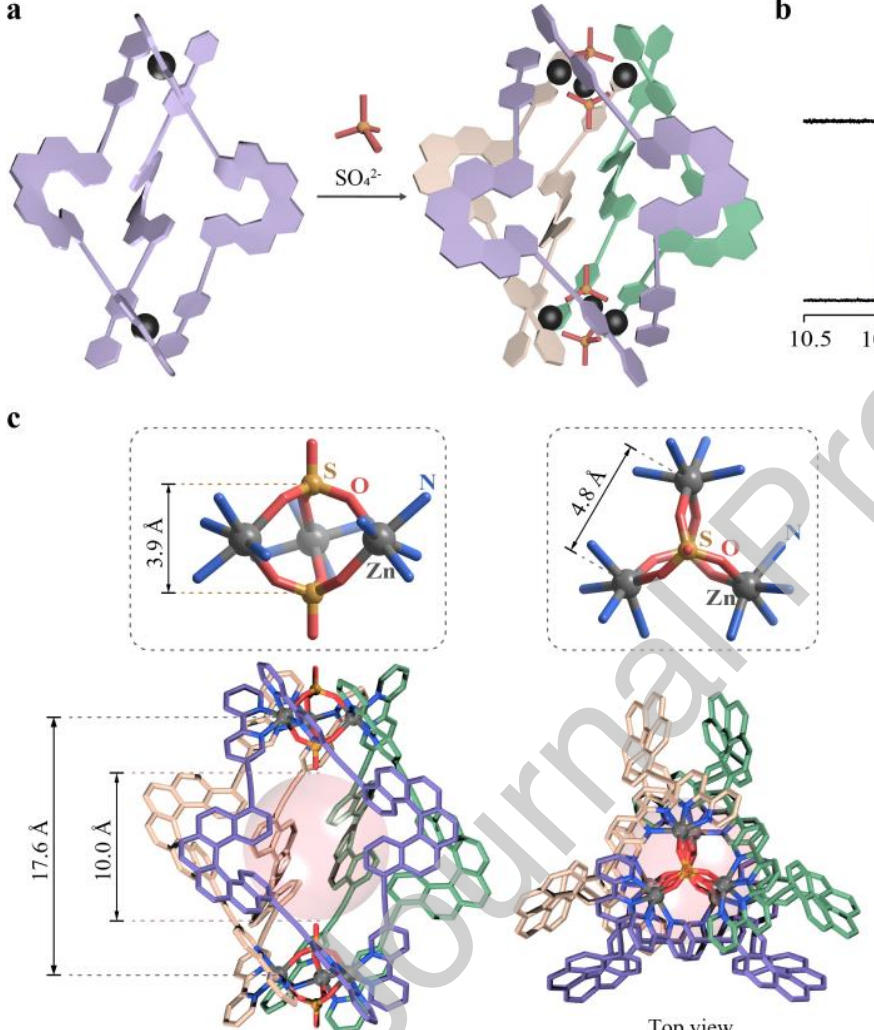

b

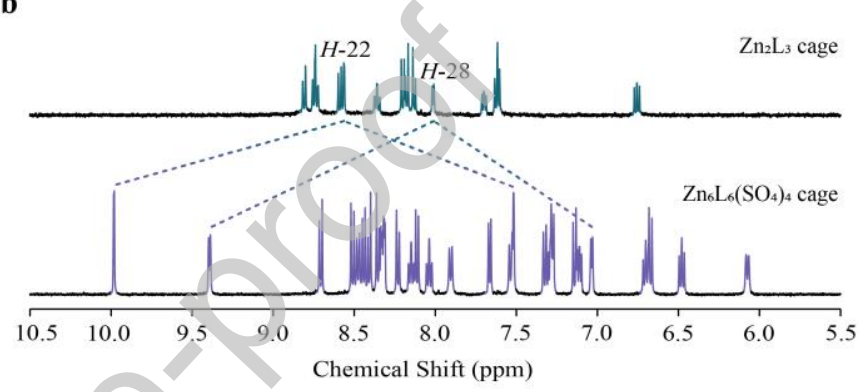

e

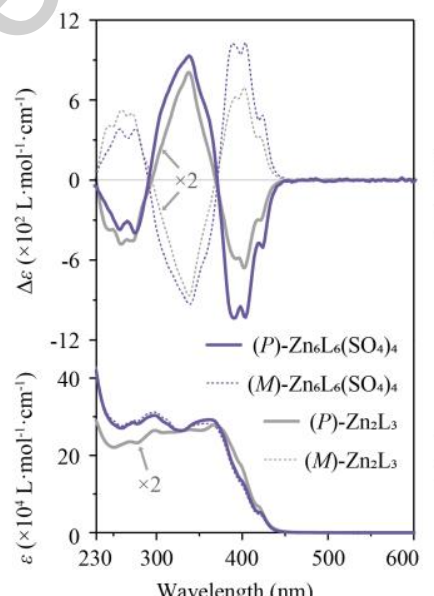

Fig. 3. Sextuple-stranded $\mathrm{Zn}_{6} \mathrm{~L}_{6}\left(\mathrm{SO}_{4}\right)_{4}$ cages. (a) Schematic representation for the synthesis of $\mathrm{Zn}_{6} \mathrm{~L}_{6}\left(\mathrm{SO}_{4}\right)_{4}$ cage. (b) ${ }^{1} \mathrm{H}$ NMR spectrum of (rac) $-\mathrm{Zn}_{6} \mathrm{~L}_{6}\left(\mathrm{SO}_{4}\right)_{4}$ cage $\left(500 \mathrm{MHz}, \mathrm{CD}_{3} \mathrm{OD}, 298 \mathrm{~K}\right.$ ) with comparison to (rac) $-\mathrm{Zn}_{2} \mathrm{~L}_{3}$ cage $\left(500 \mathrm{MHz}, \mathrm{CD}_{3} \mathrm{OD}, 298 \mathrm{~K}\right)$. (c) Crystal structure of (rac) $-\mathrm{Zn}_{6} \mathrm{~L}_{6}\left(\mathrm{SO}_{4}\right)_{4}$ cage with the largest possible sphere inside the cavity, and partially enlarged views of the $\mathrm{Zn}_{3}\left(\mathrm{SO}_{4}\right)_{2}$ cluster. (d) $\mathrm{UV}$-vis (bottom) and ECD (top) spectra of enantiopure $\mathrm{Zn}_{6} \mathrm{~L}_{6}\left(\mathrm{SO}_{4}\right)_{4}$ (in $\mathrm{CH}_{3} \mathrm{OH}, c=1 \times 10^{-5} \mathrm{~mol} / \mathrm{L}$ ) and $\mathrm{Zn}_{2} \mathrm{~L}_{3}$ cages (the intensity for $\mathrm{Zn}_{2} \mathrm{~L}_{3}$ cages were doubled for clearer comparison). (e) Fluorescence (bottom) and CPL (top) spectra of enantiopure $\mathrm{Zn}_{6} \mathrm{~L}_{6}\left(\mathrm{SO}_{4}\right)_{4}$ cages. The inset photograph shows the luminescence under irradiation at $365 \mathrm{~nm}$.

\section{Declaration of competing interest}

The authors declare that they have no known competing financial interests or personal relationships that could have appeared to influence the work reported in this paper.

\section{Acknowledgments}

This work was supported by the National Key R\&D Program of China (No. 2020YFA0908100), the National Natural Science Foundation of China (Nos. 92056110 and 22075180), the Science and Technology Commission of Shanghai Municipality (Nos.
18JC1415500, 195271040, 20JC1415000). The authors thank Prof. Shunai Che's group in Tongji University for assistance with CPL measurement.

\section{References}

[1] R. Chakrabarty, P.S. Mukherjee, P.J. Stang, Chem. Rev. 111 (2011) 6810-6918.

[2] T. Hasell, A.I. Cooper, Nat. Rev. Mater. 1 (2016) 16053.

[3] M.M.J. Smulders, I.A. Riddell, C. Browne, et al., Chem. Soc. Rev. 42 (2013) 1728-1754. 
[4] A.M. Castilla, W.J. Ramsay, J.R. Nitschke, Acc. Chem. Res. 47 (2014) 2063-2073.

[5] R. Custelcean, Chem. Soc. Rev. 43 (2014) 1813-1824.

[6] G. Zhang, M. Mastalerz, Chem. Soc. Rev. 43 (2014) 1934-1947.

[7] W. Wang, Y.X. Wang, H.B. Yang, Chem. Soc. Rev. 45 (2016) 2656-2693.

[8] G.H. Clever, P. Punt, Acc. Chem. Res. 50 (2017) 2233-2243.

[9] T.R. Cook, P.J. Stang, Chem. Rev. 115 (2015) 7001-7045.

[10] H. Amouri, C. Desmarets, J. Moussa, Chem. Rev. 112 (2012) 2015-2041.

[11] S. Zarra, D.M. Wood, D.A. Roberts, et al., Chem. Soc. Rev. 44 (2015) 419-432.

[12] D. Zhang, T.K. Ronson, J.R. Nitschke, Acc. Chem. Res. 51 (2018) 2423-2436.

[13] M. Yoshizawa, J.K. Klosterman, M. Fujita, Angew. Chem. Int. Ed. 48 (2009) 3418-3438.

[14] C.J. Brown, F.D. Toste, R.G. Bergman, et al., Chem. Rev. 115 (2015) 3012-3035.

[15] S.H.A.M. Leenders, R. Gramage-Doria, B. de Bruin, et al., Chem. Soc. Rev. 44 (2015) 433-448.

[16] T. Hasell, M.A. Little, S.Y. Chong, et al., Nanoscale 9 (2017) 6783-6790.

[17] P. Howlader, E. Zangrando, P.S. Mukherjee, J. Am. Chem. Soc. 142 (2020) 9070-9078.

[18] L.J. Chen, H.B. Yang, M. Shionoya, Chem. Soc. Rev. 46 (2017) $2555-2576$.

[19] M. Pan, K. Wu, J.H. Zhang, et al., Coord. Chem. Rev. 378 (2019) 333-349.

[20] A. Lützen, M. Hapke, J. Griep-Raming, et al., Angew. Chem. Int. Ed. 41 (2002) 2086-2089.

[21] J. Bunzen, T. Bruhn, G. Bringmann, et al., J. Am. Chem. Soc. 131 (2009) 3621-3630.

[22] C. Gütz, R. Hovorka, N. Struch, et al., J. Am. Chem. Soc. 136 (2014) 11830-11838.
[23] Y. Shen, C.F. Chen, Chem. Rev. 112 (2012) 1463-1535.

[24] M. Gingras, Chem. Soc. Rev. 42 (2013) 968-1006.

[25] K. Dhbaibi, L. Favereau, J. Crassous, Chem. Rev. 119 (2019) 8846-8953.

[26] C. Shen, G. Loas, M. Srebro-Hooper, et al., Angew. Chem. Int. Ed. 55 (2016) 8062-8066.

[27] K. Dhbaibi, L. Favereau, M. Srebro-Hooper, et al., Chem. Sci. 9 (2018) 735-742.

[28] J. Barroso, J.L. Cabellos, S. Pan, et al., Chem. Commum. 54 (2018) 188-191.

[29] A.U. Malik, F. Gan, C. Shen, et al., J. Am. Chem. Soc. 140 (2018) 2769-2772.

[30] T.R. Schulte, J.J. Holstein, G.H. Clever, Angew. Chem. Int. Ed. 58 (2019) 5562-5566.

[31] T. Damhus, C.E. SchäFfer, Inorg. Chem. 22 (1983) 2406-2412.

[32] E.M. Kober, T.J. Meyer, Inorg. Chem. 21 (1982) 3967-3977.

[33] P. Bonakdarzadeh, F. Pan, E. Kalenius, et al., Angew. Chem. Int. Ed. 54 (2015) 14890-14893.

[34] N. Struch, C. Frömbgen, G. Schnakenburg, et al., Eur. J. Org. Chem. (2017) 4984-4989.

[35] M. Ziegler, A. von Zelewsky, Coord. Chem. Rev. 177 (1998) 257-300.

[36] G. Auböck, M. Chergui, Nat. Chem. 7 (2015) 629-633.

[37] Q.T. He, X.P. Li, Y. Liu, et al., Angew. Chem. Int. Ed. 48 (2009) 6156-6159.

[38] S.H.R.W. Singh, H.L.C. Feltham, S. Brooker, Dalt. Trans. 48 (2019) 15435-15444.

[39] K.D. Oyler, F.J. Coughlin, S. Bernhard, J. Am. Chem. Soc. 129 (2007) 210-217.

[40] C.T. McTernan, T.K. Ronson, J.R. Nitschke, J. Am. Chem. Soc. 143 (2021) 664-670.

[41] E.S. Gauthier, R. Rodríguez, J. Crassous, Angew. Chem. Int. Ed. 59 (2020) 22840-22856. 


\section{Graphical abstract}

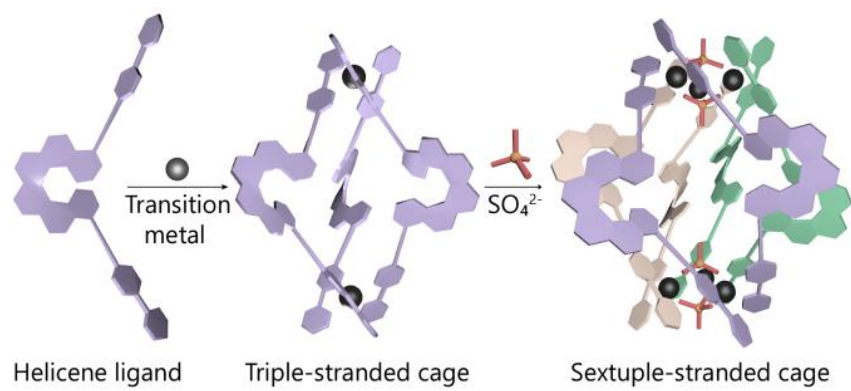

Coordination of bis-dipyridine-terminated helicene ligands with a variety of transition metals leads to the formation of various triple-stranded binuclear chiral cages and the addition of sulfate further promotes the transformation to sextuplestranded hexanuclear chiral cages. 